\title{
What was the surface temperature in central Antarctica during the last glacial maximum?
}

\author{
Thomas Blunier ${ }^{\mathrm{a}, *}$, Jakob Schwander ${ }^{\mathrm{a}}$, Jérôme Chappellaz ${ }^{\mathrm{b}}$, \\ Frédéric Parrenin ${ }^{\mathrm{b}}$, Jean Marc Barnola ${ }^{\mathrm{b}}$ \\ a Climate and Environmental Physics, Physics Institute, University of Bern, Sidlerstrasse 5, CH-3012 Bern, Switzerland \\ b CNRS Laboratoire de Glaciologie et Géophysique de l'Environnement (LGGE), BP 96, 38402 St Martin d'Hères Cedex, France
}

Received 10 June 2003; received in revised form 11 November 2003; accepted 13 November 2003

\begin{abstract}
The temperature increase at Vostok (Antarctica) from the last glacial maximum to the present warm period is about $8^{\circ} \mathrm{C}$ based on the deuterium isotope profile. The bore hole temperature (temperature profile in the ice sheet) indicates that the temperature difference may have been much larger, about $15^{\circ} \mathrm{C}$. The temperature dependent gas occlusion process is the key to evaluate the two scenarios. Atmospheric air penetrates the porous firn layer of the ice sheet and gets trapped at the firn ice boundary. Consequently the air is younger than the surrounding ice when it gets enclosed in bubbles. This age difference ( $\Delta$ age) between ice and enclosed gas is temperature and accumulation rate dependent. Therefore it is possible to estimate paleotemperatures from a known $\Delta$ age. We use the linkage between chronologies of $\mathrm{CH}_{4}$ and water isotopes from Byrd station and Vostok to obtain an experimental $\Delta$ age for Vostok. This experimental $\Delta$ age is then compared to modeled $\Delta$ age for the two temperature scenarios. Our results indicate that the temperature reconstruction deduced from the water isotopic composition is the more probable one.
\end{abstract}

(C) 2003 Elsevier B.V. All rights reserved.

Keywords: ice core; Antarctic temperature; gas occlusion; last glacial maximum

\section{Introduction}

Local temperature from ice cores can be reconstructed using the temperature dependence of the isotopic composition of precipitation. The isotopic composition is translated into a local surface temperature with a linear relationship between the annual mean temperature and the annual mean

\footnotetext{
* Corresponding author. Tel.: +41-(0)31-631-44-71.
}

E-mail address: blunier@climate.unibe.ch (T. Blunier). isotope value. The slope is that of today's spatial relationship; thus assuming that the temporal slope (at one site) is identical to the spatial slope (today). These paleotemperature reconstructions have been questioned by surface temperature estimates from bore hole temperature measurements [1-3]. The temperature at the surface of the ice sheet defines the heat flow to depth. The resulting temperature profile, measured in a bore hole of a deep drilling, can be used to reconstruct past surface temperature by inverse modeling. Unfortunately bore hole temperature measurements have not the time resolution to resolve fast climatic 
changes such as Dansgaard-Oeschger events or the Younger Dryas, nor do they give access to surface temperature changes older than the late glacial. However, the bore hole approach is well suited to reconstruct the long term glacial-interglacial temperature difference. The result of this exercise is a significantly lower last glacial (LG) temperature than suggested from the water isotope variations for both Greenland and Antarctic sites.

For central Greenland the spatial relation between $\delta^{18} \mathrm{O}$ and temperature is $0.67 \% \circ /{ }^{\circ} \mathrm{C}$ today $[4,5]$. Based on the bore hole temperature, and confirmed by various independent studies, the relation was rather $0.33 \% \circ /{ }^{\circ} \mathrm{C}$ in the past $[2,3,6-8]$. Thus the glacial-interglacial temperature difference was on the order of $20^{\circ} \mathrm{C}$. The relation based on the bore hole temperature remained probably valid over the fast interstadial temperature changes to the early Holocene [6-8]. Model studies suggest that, for central Greenland, the slope in the past is different of today's spatial slope due to a change in the precipitation seasonality (see [9] and references therein).

For central Antarctica the spatial relationship between the water isotopic composition and surface temperature estimates a temperature difference of $7-10^{\circ} \mathrm{C}$ between the LG and the present interglacial [10,11]. Today the slope between water isotopes and local temperature is $6.04 \% \mathrm{o} /$ ${ }^{\circ} \mathrm{C}$ for $\delta \mathrm{D}$ for Vostok [11], and $0.99 \% \circ /{ }^{\circ} \mathrm{C}$ for $\delta^{18} \mathrm{O}$ for Byrd station [10]. Model calculations indicate that this spatial relationship was basically valid throughout the LG [11-14]. A study based on the thermal fractionation of nitrogen and argon isotopes at $108 \mathrm{kyr} \mathrm{BP}$, the transition of isotope stage $5 \mathrm{~d} / 5 \mathrm{c}$ [15], suggests that the spatial relationship may slightly underestimate the temperature difference between $108 \mathrm{kyr} \mathrm{BP}$ and today by $20 \pm 15 \%$ [15]. On the other hand deuterium excess data suggest that the Holocene-LG temperature difference is slightly reduced compared to the spatial relationship [16]. This study is an extension to the spatial relationship and takes into account temperature changes at the source region of precipitation at Vostok.

The water isotope based temperature reconstruction is questioned by a study based on bore hole temperature measurements at Vostok which roughly doubles the Vostok glacial-interglacial temperature difference. Salamatin et al. [1] established an independent time scale for the Vostok ice core. This time scale is based on the assumption that the orbital signal (harmonics of Milankovich periods) is imprinted in the surface temperature and therefore also in the bore hole temperature record. Using this chronology Salamatin et al. are able to compare the bore hole temperature record to bore hole temperature records modeled from surface temperature. They

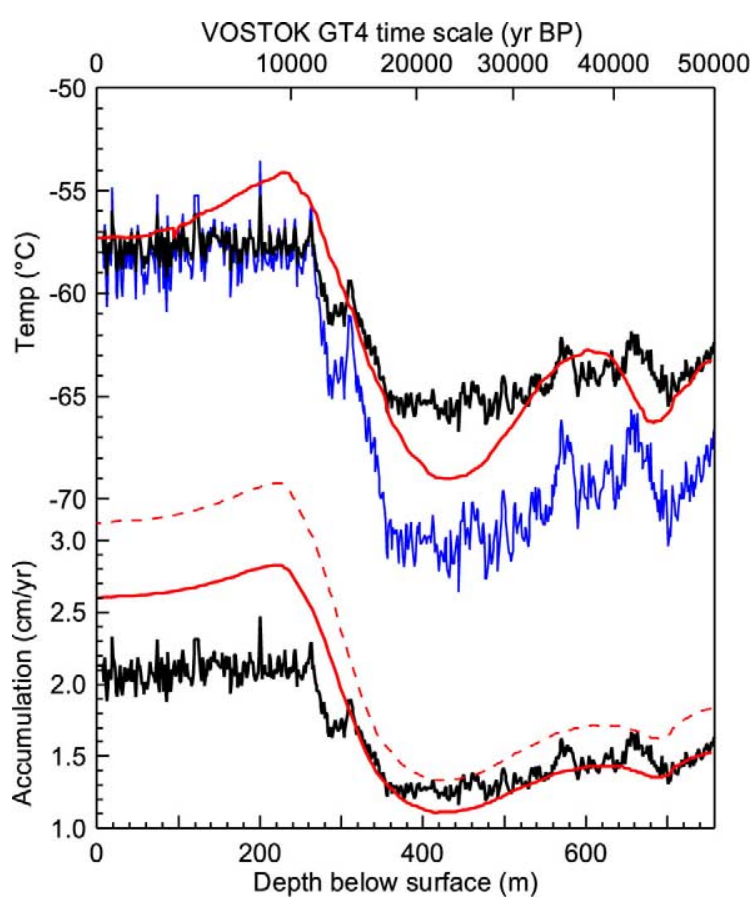

Fig. 1. Temperature and accumulation rate time series for Vostok used as input for the densification model. Heavy black lines: Temperature [23] and accumulation rate [32] used for the 'standard' $\left(T_{\mathrm{WI}}\right)$ scenario. Light black (blue) line: For this scenario $\left(T_{\mathrm{BH}} 2\right)$ the $T_{\mathrm{WI}}$ temperature record was stretched so that the increase from the last glacial to the Holocene becomes $15^{\circ} \mathrm{C}$. Grey (red) lines: Original temperature and accumulation rate from Salamatin et al. [1] (fig. 5, Scenario 1) used for our scenario $T_{\mathrm{BH}} 1$. Dashed line: $T_{\mathrm{BH}} 1$ with a $20 \%$ increased accumulation rate. For the calculation of the $T_{\mathrm{BH}}$ scenarios we used the corresponding time scale from Salamatin et al. For the presentation in Fig. 3 we transferred the results to the GT4 time scale. (For colour see online version.) 
observe that the modeled temperature agrees best to the measured temperature when the isotopic surface temperature (slope $6.04 \% \circ /{ }^{\circ} \mathrm{C}$ ) is allowed more intense precession oscillations. The result is a LG surface temperature which is $15^{\circ} \mathrm{C}$ lower than during the early Holocene, nearly doubling the estimate from today's spatial relationship between the water isotopic composition and surface temperature (see Fig. 1). The isotopic value is linked to the temperature where snow forms. In Antarctica this is assumed to be just above the inversion layer. Today the inversion layer temperature change is 0.67 times the surface temperature variation at Vostok [11]. Salamatin et al. suggest that the relationship between inversion and surface temperature was not constant in the past to explain the disaccord between isotope and bore hole based temperature estimates.

An independent way to judge past temperature estimates comes from the gas occlusion process. The uppermost part of the ice sheet called firn is permeable. Thus gases get occluded but in a depth of $50-150 \mathrm{~m}$ below surface. The consequence is that the occluded gas is younger than the surrounding ice. The firnification process and the resulting age difference ( $\Delta$ age) and the associated close off depth (COD) are sensitive to temperature and accumulation rate. The processes are well understood and it is possible to calculate $\Delta$ age with a model. The model allows to investigate which temperature results in a $\Delta$ age compatible with observed $\Delta$ age. With this method it was possible to show that the Greenland surface temperature derived from bore hole temperature is the more probable one for the fast temperature changes in the LG [6]. We will apply the $\Delta$ age method to the Vostok ice core to evaluate the surface temperature reconstructions derived from water isotope $\left(T_{\mathrm{WI}}\right)$ and bore hole temperature $\left(T_{\mathrm{BH}}\right)$ over the last $50 \mathrm{kyr}$.

\section{Outline of the method}

For the Greenland sites an empirical estimate of $\Delta$ age was deduced from climatic events recorded simultaneously in the gas and in the ice record, namely the atmospheric $\mathrm{CH}_{4}$ concentra- tion and $\delta^{18} \mathrm{O}[6]$. The reconstruction was thus based on data from one core.

For Antarctic sites the global $\mathrm{CH}_{4}$ signal (neglecting the bipolar concentration difference of a few percent) is generally not synchronous to the $\delta^{18} \mathrm{O}$ or $\delta \mathrm{D}$ signal [17]. Therefore water isotopes and $\mathrm{CH}_{4}$ records from two Antarctic ice cores from sites with very different accumulation rate/ temperature conditions have to be combined to deduce an empirical $\Delta$ age.

Accumulation and temperature vary largely over the Antarctic continent and $\Delta$ age changes from a few hundred to several thousand years depending on the site. Varying the glacial temperature estimate will also change $\Delta$ age by centuries to millennia depending on the site. Starting from synchronized isotope records from two sites, the two $\mathrm{CH}_{4}$ records will be synchronous only if the proper temperature scenario is used. This provides us with the tool to test temperature scenarios. The more $\Delta$ age differs between the two sites the more sensitive is the test. Byrd and Vostok stations have very different climatic conditions. While $\Delta$ age at Byrd station is only a few hundred years under present day conditions, reaching up to $\sim 1 \mathrm{kyr}$ for the $\mathrm{LG}$, this difference reaches several thousand years for Vostok. As for the Greenland debate [6] we will compare calculated $\Delta$ age estimates for different temperature scenarios to observed $\Delta$ ages. To obtain an experimental $\Delta$ age for Vostok the procedure is as follows (see Section 4 for details and discussion): (1) The Byrd station and Vostok isotope records are put on the same time scale by synchronizing the records. (2) The gas age for the Byrd station $\mathrm{CH}_{4}$ data is calculated (see also Section 3). (3) The Vostok $\mathrm{CH}_{4}$ record is synchronized to the Byrd $\mathrm{CH}_{4}$ record. From this exercise a gas age is assigned to each Vostok depth where there is a $\mathrm{CH}_{4}$ value. Vostok $\Delta$ age is the difference between ice age and gas age for individual $\mathrm{CH}_{4}$ samples.

\section{3. $\Delta$ age calculation}

$\Delta$ age under different climatic conditions can be assessed by the determination of the depth of the firn-ice transition and the age of the ice at this 
depth using a firn densification model on one hand and calculation of the age of the air at the transition depth with a diffusion model on the other hand. Generally the two terms are separated by one to two orders of magnitude, the age of the ice at the firn-ice transition being in the range of centuries to millennia and the age of the air being a few decades at most. The densification was calculated according to Schwander et al. [6] making use of a dynamical version of the empirical densification model by Herron and Langway $[6,18]$ from the surface density (taken as $350 \mathrm{~kg} \mathrm{~m}^{-3}$ ) to a density of $550 \mathrm{~kg} \mathrm{~m}^{-3}$ and the semi-empirical model by Pimienta and Barnola [19] for denser strata. The model includes the heat transfer in the firn. This is important calculating $\Delta$ age over periods of climate change where the firn temperature versus depth is not constant in time affecting the densification process.

In order to calculate the age of the ice at the bubble COD the close off density under past climatic conditions has to be known. Based on total gas content measurements Martinerie et al. [20] describe the close off density as a function of temperature and pure ice density. A present day firn air study at central Greenland shows that the air is isolated at a density $14 \mathrm{~kg} \mathrm{~m}^{-3}$ lower than estimated from total gas content measurements [6]. This difference is due to the presence of a non-diffusive zone above the COD. For our $\Delta$ age calculations we reduce the close off density obtained by the Martinerie equation by $14 \mathrm{~kg}$ $\mathrm{m}^{-3}$ assuming that the density difference between air occlusion and air isolation is also applicable to other sites.

The age of the air at the COD is relatively small compared to the age of the ice. Under present day conditions it is less than 2\% (Byrd and Vostok stations) of the $\Delta$ age and its portion is decreasing for colder climate. Therefore we parameterize the age of the air according to the Greenland results [6] assuming that the diffusive equilibration time is proportional to the square of the firn thickness and that diffusivity is proportional to $T^{1.85}$ [21]. $\Delta$ age can now be calculated as the difference between the age of the ice deduced from the densification model and the approximated age of the air.
Data used to determine the parameters of the densification model cover a temperature range from -13 to $-57^{\circ} \mathrm{C}$ and accumulation rates from 0.02 to $0.5 \mathrm{~m}$ water equivalent based on present day conditions at various sites. Also the data used to obtain the close off density cover the temperature range from -13 to $-57^{\circ} \mathrm{C}$. This range includes all present and past temperature and accumulation rates for Byrd station over the last $50 \mathrm{kyr}$. Under present day conditions, the close off ages given by the Pimienta-Barnola model deviate by less than $4 \%$ from observations [19].

\section{Observed $\triangle$ age and COD at Vostok}

We now experimentally assess $\Delta$ age and COD for the Vostok ice core. To do this we need to deduce the Vostok gas time scale independently. We obtain this time scale by synchronizing the Vostok $\mathrm{CH}_{4}$ record to the Byrd $\mathrm{CH}_{4}$ record. We arbitrary chose the Vostok GT4 time scale as the reference time scale for our study. The choice of the reference time scale has some influence on the resulting $\Delta$ age which we will discuss later.

First the Byrd station time scale has to be synchronized to the Vostok GT4 reference time scale. Although Byrd and Vostok isotope records do not change in concert at all times, e.g. Byrd station indicates a temperature minimum before the deglaciation which is not seen in the Vostok record, they share major temperature events allowing a reasonable synchronization. We have matched the Byrd $\delta^{18} \mathrm{O}$ record [22] to the Vostok $\delta \mathrm{D}$ record [23] by linear interpolation between match points chosen at prominent spots (match points are shown in Fig. 2). Obviously this is not a high precision synchronization. We estimate that the match is off by no more than $1 \mathrm{kyr}$ at the match points, with an increasing uncertainty of $100 \mathrm{yr}$ per $1000 \mathrm{yr}$ distance from the nearest match point. The synchronization is confirmed by the close match of the Vostok [24] and Byrd $[25]{ }^{10} \mathrm{Be}$ peak located in the middle of two match points around $37 \mathrm{kyr}$ BP on the GT4 time scale. An independent match of the isotopic signals is within the estimated uncertainty [26]. 


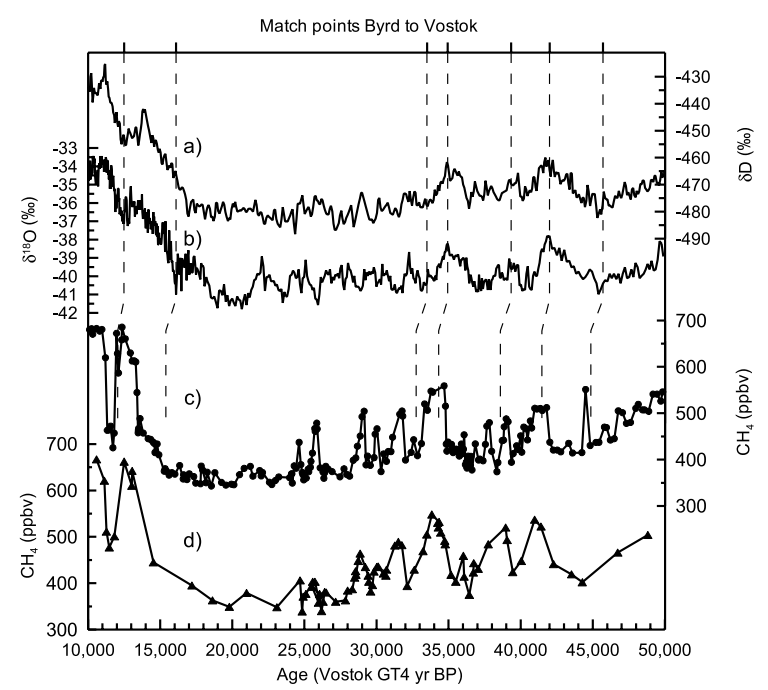

Fig. 2. Isotopic and $\mathrm{CH}_{4}$ data from the Vostok and Byrd ice cores. All data are presented on the Vostok GT4 time scale [32]. Dotted lines indicate where the Byrd $\delta^{18} \mathrm{O}$ record was matched to the Vostok $\delta \mathrm{D}$ record. Ages in between these points were interpolated linearly. The dotted lines also show where the match points are found in the Byrd $\mathrm{CH}_{4}$ record. The age difference between a match point in the $\delta^{18} \mathrm{O}$ and the $\mathrm{CH}_{4}$ record equals $\Delta$ age. (a) $\delta \mathrm{D}$ record from Vostok station [23]. (b) $\delta^{18} \mathrm{O}$ record from Byrd station [22]. (c) Byrd $\mathrm{CH}_{4}$ record [17]. (d) Vostok $\mathrm{CH}_{4}$ record [32]. The Vostok $\mathrm{CH}_{4}$ record is matched directly to the Byrd $\mathrm{CH}_{4}$ record (see text).

We now calculate a Byrd gas age time scale applying the densification model. $\Delta$ age for Byrd station is calculated for two temperature scenarios. The higher scenario $\left(T_{\mathrm{WI}}\right)$ is derived from today's spatial relation between temperature and $\delta^{18} \mathrm{O}$ for Byrd [10]. For the lower temperature scenario $\left(T_{\mathrm{BH}}\right)$ we refer to the results from Salamatin et al. [1] and increase the LG-Holocene temperature difference to $15^{\circ} \mathrm{C}$. The accumulation rate was calculated following the approach from Jouzel et al. [23] assuming a linear relation between accumulation rate and the derivative of the rate between water vapor partial pressure and temperature with respect to temperature. $\Delta$ ages for $T_{\mathrm{WI}}$ and $T_{\mathrm{BH}}$ differ by $\sim 700 \mathrm{yr}$ during the last glacial maximum and less elsewhere. To account for some uncertainty in the Byrd station accumulation rate we decrease/increase the calculated accumulation rate by $10 \%$ for $T_{\mathrm{BH}}$ and $T_{\mathrm{WI}}$, respectively. This increases the difference between
$\Delta$ age for $T_{\mathrm{WI}}$ and $T_{\mathrm{BH}}$ by $\sim 150 \mathrm{yr}$ for the last glacial maximum. We continue with the mean gas age time scale from the two scenarios.

To obtain a gas age time scale for Vostok we synchronized the Vostok methane record with the Byrd methane record now on the GT4 time scale. We used a Monte Carlo method to search for a maximal correlation between the $\mathrm{CH}_{4}$ records [6] Fig. 2 shows the result of this synchronization.

We obtain an experimental $\Delta$ age for Vostok subtracting the gas age from the ice age at the same depth. That is for each $\mathrm{CH}_{4}$ data point in the Vostok record. To estimate the total uncertainty of the experimental $\Delta$ age we use a bootstrap method which propagates the uncertainty of the isotope synchronization from Byrd and Vostok, the range of $\Delta$ age for Byrd for the two temperature scenarios (including $\pm 10 \%$ accumulation variation), and the uncertainty of the synchronization of the $\mathrm{CH}_{4}$ records.

In a similar way we are able to deduce COD from the gas age and ice age time scales. We start out from the $\Delta$ depth, the layer of ice between ice and gas of the same age. This layer was thinned during its flow from the surface to the actual depth in the ice sheet. To obtain the COD we have to take into account this thinning of the initial ice layer which is calculated from the GT4 time scale and the densification from firn to ice. The initial equivalent ice layer is $\sim 0.7$ times the COD. Variations of this value are low within $5 \%$ for all climate conditions regarded here. We are now able to compare this experimental $\triangle$ age and COD for the Vostok ice core to the modeled values.

\section{Validity of the densification model for Vostok glacial conditions}

Vostok glacial conditions have no present day analog and we have no direct evidence that the densification model remains valid for these conditions. All the models presently in use are to some point empirical. The parameters are tuned to the present density profiles. The modeled $\Delta$ age for Vostok glacial conditions could deviate from the true $\Delta$ age due to an imperfect parameterization of 
the densification process itself or due to a flawed estimate of the close off density. For Vostok the age of the firn layer where the air is isolated from the atmosphere calculated by different models agrees within about \pm 100 yr for present conditions [27]. For glacial conditions the model predicted $\Delta$ ages deviate more. However, for the whole range of purely empirical to more or less physical models the range of predicted $\Delta$ ages is only about $\pm 500 \mathrm{yr}$ [27]. We are therefore confident that the densification model is reasonable also for Vostok last glacial conditions.

Another critical point is the estimated density, and the corresponding depth, where the air is finally isolated from the atmosphere. The close off density can be determined in several ways. We calculate close off density based on the study of total air content from several sites [20,28] and correct it for the non-diffusive zone (see above for details). Not applying this correction leads to an increased $\Delta$ age of about $1 \mathrm{kyr}$. On the other hand total air content has been measured along the Vostok core and past close off density can be estimated directly from these measurements, assuming that the atmospheric pressure at the close off did not change. Still, there exist only a few total air content measurements over the period examined here [20]. Arnaud et al. [27] compare $\Delta$ age calculated with close off densities estimated directly from past total air contents at Vostok to $\Delta$ age calculated with the method used here extrapolating from present total air contents from different sites. The resulting $\Delta$ ages deviate only by a few hundred years.

An experimental estimate for the COD is the diffusive column height (DCH) derived from the gravitational enrichment of $\delta^{15} \mathrm{~N}$ with depth under constant (steady state) climatic conditions [29]. The DCH is always smaller than the COD as it does not include the convective zone on top and the non-diffusive zone at the bottom of the firn column [29]. For high accumulation sites DCH from $\delta^{15} \mathrm{~N}$ are generally in agreement with the densification model. However, for low accumulation sites like Vostok the DCH for the glacial period derived from $\delta^{15} \mathrm{~N}$ values are up to $60 \mathrm{~m}$ lower than the calculated COD [29-31]. This is also the case at the Vostok $5 \mathrm{~d} / 5 \mathrm{c}$ transition where
Caillon et al. [15] find an experimental COD of 123-135 m and a DCH of $84-86 \mathrm{~m}$ calculated from $\delta^{15} \mathrm{~N}$ measurements. Such a large difference can hardly be explained by an increased convective or non-diffusive zone during the glacial. We do not have an explanation for this discrepancy.
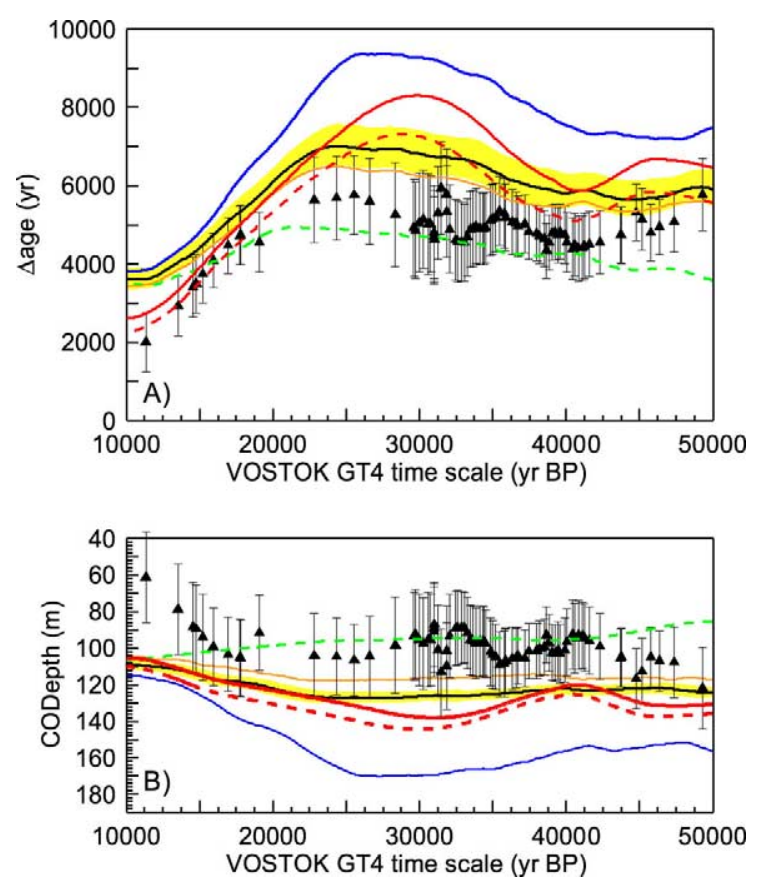

Fig. 3. $\Delta$ age (A) and COD (B) for the Vostok ice core on the GT4 time scale [32]. Black lines: Model calculations obtained with the 'standard' ( $\left.T_{\mathrm{WI}}\right)$ Vostok temperature [23] and GT4 accumulation rate (today's surface temperature has been taken as $-57.3^{\circ} \mathrm{C}$ ). The grey (yellow) areas show $\Delta$ age and COD obtained with $T_{\mathrm{WI}}$ and GT4 accumulation rates varied by $\pm 10 \%$. Thin dashed (orange) lines: Model calculations obtained with a temperature estimate taking into account the changes in the precipitation source region based on deuterium excess measurements [16]. Thin black (blue) lines: Model calculations obtained with the $T_{\mathrm{BH}} 2$ scenario and GT4 accumulation rate. Grey (red) lines: Model calculations obtained for the $T_{\mathrm{BH}} 1$ scenario (Salamatin et al. [1], fig. 5, Scenario 1 and the corresponding time scale) (heavy line) and with a $20 \%$ increased accumulation rate (dashed line). Heavy green dashed lines: COD obtained from $\delta^{15} \mathrm{~N}$ [29] (12 $\mathrm{m}$ have been added to account for the convective zone [34]). $\Delta$ age has been obtained using the model with the standard parameters forcing close off at the $\delta^{15} \mathrm{~N}$ implied COD. Triangles: $\triangle$ age and COD obtained independently by synchronizing the Byrd and Vostok records (see text). (For colour see online version.) 
Indeed the empirically determined COD of $123-135 \mathrm{~m}$ at the Vostok $5 \mathrm{~d} / 5 \mathrm{c}$ transition, and probably also at termination III [31], is compatible with the modeled COD. This and the coherency between models of different make gives us confidence in the $\Delta$ age models also for climatic conditions exceeding the range of the calibration. It is at present still the best estimate for COD and $\Delta$ age. The accuracy for $\Delta$ age calculations is expected to be within $10 \%$ of $\Delta$ age for Vostok [27].

\section{Results and discussion}

We now compare observed $\triangle$ age and COD at Vostok with calculated $\Delta$ age and COD for $T_{\mathrm{BH}}$ and $T_{\mathrm{WI}}$ estimates (Fig. 3). Calculations were made for the following scenarios (see Fig. 1): $T_{\mathrm{WI}}$ with the standard isotope temperature [23] and accumulation rate corresponding to the GT4 time scale [32], $T_{\mathrm{BH}} 1$ where temperature and accumulation rate correspond to Scenario 1 in fig. 5 of Salamatin et al. [1], $T_{\mathrm{BH}} 2$ is identical to $T_{\mathrm{WI}}$ but the temperature increase from the last glacial to the Holocene is stretched to become $15^{\circ} \mathrm{C}$ [1]. Present day temperature was taken as $-57.3^{\circ} \mathrm{C}$ [33] for all calculations. We also compare our empirical $\Delta$ age and COD to COD and $\Delta$ age deduced from $\delta^{15} \mathrm{~N}$ data. $\delta^{15} \mathrm{~N}$ is a measure for the DCH which does not account for the well mixed convective zone. We obtain an estimate of COD by adding $12 \mathrm{~m} \mathrm{[34]} \mathrm{to} \mathrm{the} \mathrm{DCH} \mathrm{obtained}$ from the $\delta^{15} \mathrm{~N}$ data [29].

Surprisingly the experimentally deduced COD fits best COD deduced from $\delta^{15} \mathrm{~N}$ measurements between 45 and $15 \mathrm{kyr}$ BP. As for the model simulations none of the calculated scenarios is able to reproduce the empirical data perfectly. Under the assumption that the densification model is in principle still valid for the Vostok glacial conditions we observe that the $T_{\mathrm{BH}}$ scenarios are unlikely. On the other hand $\Delta$ age (COD) calculated with the 'standard' isotopic temperature reconstruction $\left(T_{\mathrm{WI}}\right)$ fit much better to the experimental $\Delta$ age (COD) reconstruction (Fig. 3, heavy black line). However, also here the calculated $\Delta$ age is often beyond the range of the experimental $\Delta$ age.
Using the COD deduced from the $\delta^{15} \mathrm{~N}$ values we can use the model to calculate a $\Delta$ age by forcing close off at the COD deduced from $\delta^{15} \mathrm{~N}$. Here it is relatively irrelevant which of the above temperature and accumulation rate scenarios is used. The consequence would be a close off at a density of about $750 \mathrm{~kg} \mathrm{~m}^{-3}$, which is in complete disagreement with gas content results. Alternatively the COD can be forced to fit the $\delta^{15} \mathrm{~N}$ deduced COD by starting out from a higher surface density. However, the magnitude of the surface density would have to be $600 \mathrm{~kg} \mathrm{~m}^{-3}$. Such a high density at the top of the firn column differs dramatically from values observed under dry sintering conditions and seems highly unlikely. However, if it should turn out to be true this would hinder an interpretation in terms of temperature scenarios as the resulting $\Delta$ age is barely sensitive to the two temperature scenarios. For now we do not think that the $\delta^{15} \mathrm{~N}$ based reconstruction for COD is a real alternative.

Is it possible to bring experimental $\Delta$ age and model calculations into agreement accounting for the uncertainties of the model input parameters? $\Delta$ age is not only dependent on temperature but also on accumulation rate. For the Vostok ice core accumulation rate and time scale are linked by an ice flow model. Orbital frequencies are imprinted in the Vostok time series [32,35] and the Vostok time scale attributes variations at orbital frequencies a correct age. Uncertainties linked with ice thinning in the depth range considered here are small. According to the GT4 time scale the annual layer thickness at $760 \mathrm{~m}$ below surface (corresponding to $50 \mathrm{kyr}$ ) is still $80 \%$ of the initial accumulation rate. Consequently the Vostok time scale and therefore also the accumulation rate is correct on average. However, the Vostok time scale may be and probably is temporary offset by several millennia. This uncertainty of the ice core time scale is obvious comparing time scales of different ice cores [17,26,35]. For Vostok a temporary offset time scale results in a temporary offset accumulation rate reconstruction and therefore to an offset $\Delta$ age. Parrenin et al. [35] estimate the uncertainty of the Vostok GT4 time scale to about $\pm 10 \%$ at $50 \mathrm{kyr}$ BP. Accordingly the accumulation rate has an uncertainty of 
roughly $\pm 10 \%$ as well. For the $T_{\mathrm{BH}}$ scenarios to agree with the experimental data the accumulation rate would have to be increased throughout the core by more than $20 \%$ for $T_{\mathrm{BH}} 1$, and over $40 \%$ for $T_{\mathrm{BH}} 2$. This is clearly outside the uncertainty of this parameter. Further, Salamatin et al. [1] suggest also a larger glacial-interglacial difference of the inversion layer temperature $\left(10^{\circ} \mathrm{C}\right)$. If the relationship between accumulation rate and the derivative of the rate between water vapor partial pressure and temperature with respect to temperature [23] remains valid, the low temperature of the $T_{\mathrm{BH}}$ scenario results in a lower accumulation rate (compared to GT4) which consequently leads to an increased $\Delta$ age. In summary, the bore hole temperature scenario with or without adjusted accumulation rate seems unlikely.

For the $T_{\mathrm{WI}}$ scenario increasing the accumulation rate by $10 \%$ does also not bring our modeled $\Delta$ age in full agreement with the data. However, the model approach by Arnaud et al. [27] leads to $\Delta$ ages about $500 \mathrm{yr}$ smaller than with our model [33]. Together with a $10 \%$ higher accumulation this model is in agreement with our data. We also calculated $\Delta$ age for the source region corrected isotopic temperature [16] and GT4 accumulation rate. Temperatures are slightly higher compared to the uncorrected isotopic temperature which results in a slightly smaller $\Delta$ age and a better match to the experimental data. In summary the discrepancy between experimental $\Delta$ age and $\Delta$ age for the $T_{\text {WI }}$ model calculation disappears with a slightly higher temperature and a 10\% increased accumulation rate. However, a higher accumulation rate is not compatible with the fact that the Vostok time scale is rather too young compared to other ice cores between 50 and $10 \mathrm{kyr}$ BP [26]. This signifies that the accumulation rate should rather be decreased to adjust the time scale to other ice core chronologies. A way out of this dilemma may be to keep the accumulation rate and to slightly change the ice flow to make the time scale older over the last part of the glacial. This results in a larger experimental $\Delta$ age bringing experimental and model $\Delta$ age together holding on to the GT4 accumulation rate.

We are aware that all densification models lack strong verification by data for Vostok glacial con- ditions, if we except the unique study on the $5 \mathrm{~d} / 5 \mathrm{c}$ transition [15]. However, the agreement between different models and their proven ability to simulate the close off process for high accumulation sites make it unlikely that they are largely offset for Vostok glacial conditions. We conclude that experimentally deduced $\Delta$ ages for Vostok are within the model and accumulation rate uncertainty for the $T_{\mathrm{WI}}$ temperature estimate which is calculated according to today's relationship between temperature and isotopic signal. All uncertainties are not able to bring the modeled $\Delta$ age estimate in agreement with the $T_{\mathrm{BH}}$ temperature estimate based on measurements of the Vostok bore hole temperature.

The model uncertainty hinders a detailed temperature reconstruction from experimental $\Delta$ age in Antarctica, at least for the moment. Additional information concerning the temperature change may come from more detailed $\mathrm{CH}_{4}$ records or from additional $\delta^{15} \mathrm{~N}$ measurements which observe thermal fractionation over periods of temperature change [15].

\section{Acknowledgements}

This work was supported by the University of Bern, the Swiss National Science Foundation, the EEC project Pole-Ocean-Pole (EVK2-2000-22067) and the Programme National d'Etude de la Dynamique du Climat of CNRS. We thank Françoise Vimeux for discussion and Kurt Cuffey and anonymous reviewers for constructive comments.[B $\boldsymbol{A} \boldsymbol{R} \boldsymbol{D}]$

\section{References}

[1] A.N. Salamatin, V.Y. Lipenkov, N.I. Barkov, J. Jouzel, J.R. Petit, D. Raynaud, Ice core age dating and paleothermometer calibration based on isotope and temperature profiles from deep boreholes at Vostok Station (East Antarctica), J. Geophys. Res. 103 (1998) 8963-8977.

[2] K.M. Cuffey, G.D. Clow, R.B. Alley, M. Stuiver, E.D. Waddington, R.W. Saltus, Large arctic temperature change at the Wisconsin-Holocene glacial transition, Science 270 (1995) 455-458.

[3] S. Johnsen, D. Dahl-Jensen, W. Dansgaard, N. Gundestrup, Greenland palaeotemperatures derived from GRIP 
bore hole temperature and ice core isotope profiles, Tellus 47B (1995) 624-629.

[4] W. Dansgaard, Stable isotopes in precipitation, Tellus 16 (1964) 436-468.

[5] S.J. Johnsen, W. Dansgaard, J.W.C. White, The origin of Arctic precipitation under present and glacial conditions, Tellus 41B (1989) 452-468.

[6] J. Schwander, T. Sowers, J.-M. Barnola, T. Blunier, B. Malaizé, A. Fuchs, Age scale of the air in the summit ice: Implication for glacial-interglacial temperature change, J. Geophys. Res. 102 (D16) (1997) 19483-19494.

[7] J.P. Severinghaus, E.J. Brook, Abrupt climate change at the end of the last glacial period inferred from trapped air in polar ice, Science 286 (1999) 930-934.

[8] M. Leuenberger, C. Lang, J. Schwander, $\delta^{15} \mathrm{~N}$ measurements as a calibration tool for the paleothermometer and gas-ice age differences. A case study for the 8200 B.P. event on GRIP ice, J. Geophys. Res. 104 (D18) (1999) 22163-22169.

[9] J. Jouzel, Calibrating the isotopic paleothermometer, Science 286 (1999) 910-911.

[10] G.de Q. Robin, The $\delta$ value-temperature relationship, in: G.de Q. Robin (Ed.), The Climatic Record in Polar Ice Sheets, Cambridge University Press, London, 1983, pp. 180-184.

[11] J. Jouzel, F. Vimeux, N. Caillon, G. Delaygue, G. Hoffmann, V. Masson-Delmotte, F. Parrenin, Magnitude of isotope/temperature scaling for interpretation of central Antarctic ice cores, J. Geophys. Res. Atmos. 108 (D12) (2003), art. no. 4361.

[12] G. Delaygue, J. Jouzel, V. Masson, R.D. Koster, E. Bard, Validity of the isotopic thermometer in central Antarctica limited impact of glacial precipitation seasonality and moisture origin, Geophys. Res. Lett. 27 (2000) 2677-2680.

[13] M.B. Hendricks, D.J. DePaolo, R.C. Cohen, Space and time variation of $\delta^{18} \mathrm{O}$ and $\delta \mathrm{D}$ in precipitation: Can paleotemperature be estimated from ice cores?, Glob. Biogeochem. Cycles 14 (2000) 851-861.

[14] M. Werner, M. Heimann, G. Hoffmann, Isotopic composition and origin of polar precipitation in present and glacial climate simulations, Tellus 53B (2001) 53-71.

[15] N. Caillon, J.P. Severinghaus, J.M. Barnola, J. Chappellaz, J. Jouzel, F. Parrenin, Estimation of temperature change and of gas age ice age difference, $108 \mathrm{kyr}$ BP, at Vostok, Antarctica, J. Geophys. Res. Atmos. 106 (D23) (2001) 31893-31901.

[16] F. Vimeux, K.M. Cuffey, J. Jouzel, New insights into Southern Hemisphere temperature changes from Vostok ice cores using deuterium excess correction, Earth Planet. Sci. Lett. 203 (2002) 829-843.

[17] T. Blunier, E.J. Brook, Timing of millennial-scale climate change in Antarctica and Greenland during the last glacial period, Science 291 (2001) 109-112.

[18] M.M. Herron, C.C. Langway Jr., Firn densification: An empirical model, J. Glaciol. 25 (1980) 373-385.

[19] J.-M. Barnola, P. Pimienta, D. Raynaud, Y.S. Korotkevich, $\mathrm{CO}_{2}$-climate relationship as deduced from the Vos- tok ice core: A re-examination based on new measurements and on a re-evaluation of the air dating, Tellus 43 (1991) 83-90.

[20] P. Martinerie, V.Y. Lipenkov, D. Raynaud, J. Chappellaz, N.I. Barkov, C. Lorius, Air content paleo record in the Vostok ice core (Antarctica): A mixed record of climatic and glaciological parameters, J. Geophys. Res. 99 (1994) 10565-10576.

[21] L. Andrussov, Diffusion in Gasen, in: K. Schäfer (Ed.), Landolt-Börnstein. Zahlenwerte und Funktionen aus Physik, Chemie, Astronomie, Geophysik, Technik Vol. 2 (5a), Springer, Berlin, 1969, pp. 516-565.

[22] S.J. Johnsen, W. Dansgaard, H.B. Clausen, C.C. Langway Jr., Oxygen isotope profiles through the Antarctic and Greenland ice sheets, Nature 235 (1972) 429-434.

[23] J. Jouzel, C. Lorius, J.R. Petit, C. Genthon, N.I. Barkov, V.M. Kotlyakov, V.M. Petrov, Vostok ice core: A continuous isotope temperature record over the last climatic cycle (160,000 years), Nature 329 (1987) 403-408.

[24] G.M. Raisbeck, F. Yiou, J. Jouzel, J.R. Petit, N.I. Barkov, E. Bard, ${ }^{10} \mathrm{Be}$ deposition at Vostok, Antarctica, during the last 50,000 years and its relationship to possible cosmogenic production variations during this period, in: E. Bard, W.S. Broecker (Eds.), The last Deglaciation: Absolute and Radiocarbon Chronologies, NATO ASI Series Vol. I 2, Springer, Berlin, Heidelberg, 1992, pp. 127-140.

[25] J. Beer, S.J. Johnsen, G. Bonani, R.C. Finkel, C.C. Langway, H. Oeschger, B. Stauffer, M. Suter, W. Woelfli, ${ }^{10} \mathrm{Be}$ peaks as time markers in polar ice cores, in: E. Bard, W.S. Broecker (Eds.), The Last Deglaciation: Absolute and Radiocarbon Chronologies, NATO ASI Series Vol. I 2, Springer, Berlin, Heidelberg, 1992, pp. 141-153.

[26] J. Schwander, J. Jouzel, C.U. Hammer, J.-R. Petit, R. Udisti, E. Wolff, A tentative chronology for the EPICA Dome Concordia ice core, Geophys. Res. Lett. 28 (2001) 4243-4246.

[27] L. Arnaud, J.-M. Barnola, P. Duval, Physical modeling of the densification of snow/firn and ice in the upper part of polar ice sheets, in: T. Hondoh (Ed.), Physics of Ice Core Records, Hokkaido University Press, Sapporo, 2000, pp. 285-305.

[28] P. Martinerie, D. Raynaud, D.M. Etheridge, J.-M. Barnola, D. Mazaudier, Physical and climatic parameters which influence the air content in polar ice, Earth Planet. Sci. Lett. 112 (1992) 1-13.

[29] T. Sowers, M. Bender, D. Raynaud, Y.S. Korotkevich, $\delta^{15} \mathrm{~N}$ of $\mathrm{N}_{2}$ in air trapped in polar ice: A tracer of gas transport in the firn and a possible constraint on ice agegas age differences, J. Geophys. Res. 97 (1992) 15683 15697.

[30] K. Kawamura, Variations of atmospheric components over the past 340,000 years from Dome Fuji deep ice core, Antarctica, Ph.D. thesis, Tohoku University, 2000.

[31] N. Caillon, J.P. Severinghaus, J. Jouzel, J.-M. Barnola, J. Kang, V.Y. Lipenkov, Timing of atmospheric $\mathrm{CO}_{2}$ and Antarctic temperature changes across termination III, Science 299 (2003) 1728-1731. 
[32] J.R. Petit, J. Jouzel, D. Raynaud, N.I. Barkov, J.M. Barnola, I. Basile, M. Bender, J. Chappellaz, M. Davis, G. Delaygue, M. Delmotte, V.M. Kotlyakov, M. Legrand, V.Y. Lipenkov, C. Lorius, L. Pepin, C. Ritz, E. Saltzman, M. Stievenard, Climate and atmospheric history of the past 420,000 years from the Vostok ice core, Antarctica, Nature 399 (1999) 429-436.

[33] C. Goujon, J.-M. Barnola, C. Ritz, Modelling the densification of polar firn including heat diffusion: Application to close-off characteristics and gas isotopic fractionation for Antarctica and Greenland, J. Geophys. Res., in press.

[34] M.L. Bender, T. Sowers, J.-M. Barnola, J. Chappellaz, Changes in $\mathrm{O}_{2} / \mathrm{N}_{2}$ ratio of the atmosphere during recent decades reflected in the composition of air in the firn at Vostok Station, Geophys. Res. Lett. 21 (1994) 189-192.

[35] F. Parrenin, J. Jouzel, C. Waelbroeck, C. Ritz, J.M. Barnola, Dating the Vostok ice core by an inverse method, J. Geophys. Res. Atmos. 106 (D23) (2001) 31837-31851. 